\title{
A STUDY OF THE VENTILATION CHARACTERISTICS INSIDE A TUNNEL TRAIN CARRIAGE
}

Mofreh M. Nassief, Mahmoud A. Hassan

\begin{abstract}
This paper presents and discusses results of study of natural ventilation in an underground train carriage. laboratory work, a train carriage model was constructed to a scale of 1: 30 and fitted with an electriclly he Various cases of roof and window openings with deflectors were studied, calculating the average temperatı case and giving an indication of good ventilation. In the numerical work, the software ANSYS Flotran [3] w solve the problem by finite elements with 50,000 nodal points. The air flow distribution inside the train wa: the form of contours. The results show the best combination of roof opening and window size with one def at 450 that gives the best air movement inside the train with a sensible temperature reduction of the heat inside the train model.
\end{abstract}

